Bond University

Research Repository

\title{
The impact of regulatory focus and word of mouth valence on search and experience attribute evaluation
}

Roy, Rajat; Naidoo, Vik

Published in:

European Journal of Marketing

DOI:

10.1108/EJM-06-2016-0367

Licence:

Other

Link to output in Bond University research repository.

Recommended citation(APA):

Roy, R., \& Naidoo, V. (2017). The impact of regulatory focus and word of mouth valence on search and experience attribute evaluation. European Journal of Marketing, 51(7-8), 1353-1373.

https://doi.org/10.1108/EJM-06-2016-0367

\section{General rights}

Copyright and moral rights for the publications made accessible in the public portal are retained by the authors and/or other copyright owners and it is a condition of accessing publications that users recognise and abide by the legal requirements associated with these rights.

For more information, or if you believe that this document breaches copyright, please contact the Bond University research repository coordinator. 


\section{The impact of regulatory focus and word of mouth valence on search and experience attribute evaluation}

\begin{tabular}{|r|l|}
\hline Version: & Pre-publication version \\
\hline Citation reference & https://www.emeraldinsight.com/doi/full/10.1108/EJM-06-2016-0367 \\
\hline Manuscript Type: & Original Article \\
\hline Keywords: & $\begin{array}{l}\text { Regulatory focus, search attribute, experience attribute, word of mouth, } \\
\text { attitude, intention }\end{array}$ \\
\hline $\begin{array}{l}\text { Cite as Roy, R. \& Naidoo, V. 2017. The impact of regulatory focus and word of mouth valuence on search } \\
\text { and experience attribute evaluation. European Journal of Marketing. } 51(7 / 8): 1353-1373 .\end{array}$ \\
\hline
\end{tabular}




\title{
The impact of regulatory focus and word of mouth valence on search and experience attribute evaluation
}

\begin{abstract}
Purpose - This paper investigates the direct and interactive effects of regulatory focus (promotion versus prevention), attribute type (search versus experience) and word of mouth valence (positive versus negative) on consumption decision for a service and a product.

Design/methodology/approach - Three empirical studies (two laboratories and a field experiment) using 'university' and 'mobile phone' as the research setting were used to test the key hypotheses.
\end{abstract}

Findings - Promotion (prevention) focused subjects preferred experience (search) attributes over their counterparts while making consumption decision. This preference was further reinforced for both promotion and prevention focused people under positive word of mouth. Under negative word of mouth, in comparison to their counterparts, promotion focused people still retained their preference for experience attributes, while prevention focused subjects reversed their preference and maintained status quo.

Research limitations/implications - Future research may validate and extend our findings by looking into the underlying process or studying additional word of mouth variables that may moderate the current findings.

Practical implications - Our findings will help managers devise a range of marketing strategies in the areas of advertising and product positioning, especially for products/services that are showcased in terms of experience and search attributes.

Originality/value - The current research is novel as no prior research has proposed and tested the two-way interaction between regulatory focus and search/experience attributes, or it's further moderation by word of mouth valence.

Keywords: Regulatory focus, search attribute, experience attribute, word of mouth, attitude, intention

Article Classification: Research paper 


\section{The impact of regulatory focus and word of mouth valence on search and experience attribute evaluation}

\section{Introduction}

It has been well established in the marketing literature that regulatory orientation of consumers systematically influences their product evaluation and choices (Roy and Ng, 2012; Chatterjee et al., 2011; Lee and Aaker, 2004; Chernev, 2004; Pham and Avnet, 2004). In particular, these studies show that when the regulatory focus of a consumer is matched with a certain type of product attribute, it results in higher persuasion and purchase intention. The literature defines two kinds of regulatory orientation (e.g., Higgins, 1997): first, a state that involves self-regulation towards achievement/advancement in life and involves a 'promotion focus' versus 'prevention focus', which involves self-regulation towards safety/security needs in life. A range of product attributes like hedonic versus utilitarian, imagery versus concrete, performance versus safety etc. have been known to moderate the effect of regulatory focus on product decisions (Roy and Phau, 2014; Chernev, 2004; Lee and Aaker, 2004). In recent times, researchers have recommended greater inquiries into how search and experience product attributes influence consumption (Hyo-Jin et al., 2014; Brakus et al., 2014). Given the role of regulatory focus in influencing choice of attributes, the current work explores how this motivational state may influence choice of search and experience attributes in product decisions (Gap 1).

On the other hand, a disparate stream of the marketing literature on word of mouth communication has identified significant influence of this focal construct on product choice and evaluations (De Matos and Rossi, 2008). In particular, word of mouth communications is known to help consumers with product/service evaluation, decision making and reduction of risk related to purchase (De Matos and Rossi, 2008; Bansal and Voyer, 2000). The literature 
also identifies that depending on the level of satisfaction and commitment with a product/service, consumers not only engage in word of mouth activity (e.g. how often and the quantity of information passed), but also decide on the word of mouth "valence"; i.e. engage in positive or negative word of mouth (De Matos and Rossi, 2008; Sweeney et al., 2005; Harrison-Walker, 2001). A limited number of studies till date have shown that the impact of regulatory focus on product decisions can be moderated by the word of mouth valence (Pentina et al., 2015; Zhang et al., 2010), albeit with interesting differences.

Zhang et al. (2010) finds when regulatory focus is matched with promotion (prevention) consumption goals, positive (negative) word of mouth is more persuasive than negative (positive) word of mouth. However, Pentina et al. (2015) reports that positive word of mouth can increase message persuasiveness and behavioural intention for prevention focused people, while there was no effect of positive review for promotion focus. Similarly, Lim and Chung (2011) report that negative (but not positive) word of mouth has an impact on evaluation of attributes in decision making, although they do not study the role of regulatory focus in their study. Given these mixed findings, the current work posits that the relationship between regulatory focus and word of mouth valence can be moderated by attribute type (search versus experience), and proposes a novel three-way interaction (Gap 2).

While the effect of word of mouth valence on message persuasiveness shows a positivity (negativity) bias for promotion (prevention) focused people (Zhang et al., 2010), these researchers confirm that further research gaps remain. For example, they do not study the effect of word of mouth valence on product attitude and choice, a variable that is important for regulatory focus literature (Motyka et al., 2014) (Gap 3). Further, the limited research that connects regulatory focus and word of mouth (Pentina et al., 2015; Zhang et al., 2010) fail to consider the recent theoretical developments in the regulatory focus literature, and just propagate their hypotheses based on match between regulatory foci and valence of 
information. For example, both Pentina et al. (2015) and Zhang et al. (2010) argue that promotion (prevention) foci are more sensitive to positive (negative) information as it helps them to achieve (avoid) positive versus negative outcomes. While the extant literature broadly supports this, the findings have to be reviewed in light of new theoretical developments in the regulatory focus area (e.g. Scholer and Higgins, 2013; Scholer et al., 2010). For example, these studies suggest that both promotion and prevention focused people are capable of risky and risk averse decisions, depending on their state of progress towards the goal. Based on these latest findings, the present work builds nuanced hypotheses for this study (Gap 4).

In addressing these research gaps, this study uses both laboratory and field experiments. Study 1 tests the influence of regulatory focus on attribute choice, study 2 uses a field experiment to test the moderating effect of word of mouth. Finally, study 3 uses a laboratory experiment and a different product category to replicate the findings from study 2 . In the next section, the relevant literature is reviewed first leading to the hypotheses, and then followed with three studies that are used to test them. The findings are then discussed along with managerial implications and directions for future research.

\section{Theoretical background}

\section{Search experience and credence (SEC) attributes}

In the marketing literature, goods and services have often been described as a bundle of attributes. In line with this, products and services can be described in terms of multiple attributes (Ekelund et al., 1995). The economics of information (EOI) literature (Nelson, 1970) also conceptualizes goods and services at attribute level, mainly in terms of search, experience, and credence attributes. Therefore, combining perspectives from the marketing 
and EOI literature, goods and services are more appropriately described in terms of search, experience, and credence attributes as most products or services can consist of one or a combination of these attributes.

Search, experience and credence (SEC) attributes in the literature have been conceptualized based on whether consumers are able to evaluate these attributes before, during or after consumption, and the level of information available to assist or deter consumers in their attribute appraisals. A direct translation from EOI literature describes search attributes as those which consumers are able to determine accurately before purchase; experience attributes can only be evaluated during consumption; while credence attributes cannot be evaluated even after consumption (Srinivasan and Till, 2002). Taking an information processing perspective, SEC attributes can also be defined based on increasing/decreasing levels of information availability or cost/difficulty consumers would experience while obtaining and evaluating attribute information about products or services (Lim and Chung, 2011).

Following this approach, search attributes are those for which relevant information can be obtained prior to consumption; information on experience attributes are not known unless the product is consumed, and for credence attributes, information is not known either prior to or even after the consumption. An appropriate example of search attribute from the banking sector could be the 'interest rate', information which can easily be ascertained by consumers from published sources. Experience attribute similarly would be 'convenient location', information which can only be experienced during consumption, while for a credence attribute like 'integrity of the bank', information cannot be ascertained either prior to or even after consuming the service (Lim and Chung, 2011). 
In the market place, the way consumers acquire search, experience or credence information can have implications for decision making. Consumers may seek information about search attributes from second hand sources like advertising, as search attributes are relatively easy to verify for accuracy (Hsieh et al., 2005). When compared to search attributes whose information can easily be verified from second hand sources, experience attributes are verified normally from first hand experiences. For example, consumers tend to rely more on others' recommendations on experience attributes rather than search attributes (Park and Lee, 2009). However, the matter of distinction between different attribute types is based on consumers' perceptions. Indeed, this perception can be influenced when marketers attempt to make more information available on experience attributes (e.g., online reviews about first hand experiences) in an attempt to transform them into search attributes, although such transformation can never be fully achieved (Yang and Mai, 2010).

There is some evidence that claims hedonic consumption to be more influenced by experience attributes because it involves close interaction with the product attributes in order to experience them (Eliashberg and Sawhney, 1994). The need to experience an attribute also suggests subjective nature of its qualities and the greater need to use one's senses to evaluate the product or service (Weathers et al., 2007). In comparison, search attributes tend to be of more objective quality and normally more credible compared to experience attributes (Weather et al., 2007, Jain and Posavac, 2004). Normally consumers are more sceptical of subjective and experiential information in advertising than objective and search information (Ford et al., 1990). Amongst all the SEC attributes, consumers are most sceptical of credence attributes (Srinivasan and Till, 2002). For the current work we focus on search and experience attributes only as extant literature argues that credence attributes may not be directly relevant to product decisions since consumers cannot evaluate them even after usage (Yang and Mai, 2010; Hsieh et al., 2005; Wright and Lynch, 1995). Research shows that 
consumers' reliance on SEC attributes for making product decisions can be a function of consumer characteristics (Klein, 1998). In a related manner, the marketing literature also argues that the choice of product information (e.g., attributes) in consumption can also be guided by an individual's motivational state like regulatory focus (Chatterjee et al., 2011; Lee and Aaker, 2004; Chernev, 2004).

Regulatory focus

According to the regulatory focus theory there are two different types of goals, namely the promotion and prevention (Higgins, 1997). Promotion goals are geared towards nurturance related needs in life, and concerns itself with advancement, accomplishment and aspirations (Avnet and Higgins, 2006; Aaker and Lee, 2006). Promotion system is further focused on ensuring gains or achieving a positive outcome. On the other hand, prevention goals involve protection, safety and responsibility needs and are more concerned with the absence of losses or negative outcomes (Avnet and Higgins, 2006; Aaker and Lee, 2006).

In the pursuit of nurturance needs, a state of advancement matters most to the promotion focus, which in other words is a state of positive deviation (i.e., a gain) from a neutral or status quo state (Scholer and Higgins, 2013). When circumstances indicate that things are going fine, these people are highly motivated to engage in stimulation and incentive seeking activities (Friedman et al., 2007). Promotion focus, is also less sensitive to negative deviations from the neutral state (Scholer and Higgins, 2013). Evidence shows that a state of promotion focus can deviate attention from negative or risky information in decision making (Shin et al., 2014; Sengupta and Zhou, 2007). For example, in support of this Sengupta and Zhou (2007) show that while making a product decision, a promotion focus can encourage preferences for experiential attributes (e.g., luxury in car) at the expense of safety features (e.g., braking features in car). 
A prevention focus on the other hand, emphasizes desired end states such as responsibility and safety (Higgins, 1997). Under this state, what matters most is the need to maintain absence of negative outcomes, and hence a safe or neutral state may be preferable in comparison to a negative state (Scholer and Higgins, 2013). When circumstances indicate that the environment is problematic, these people are even willing to engage risky tactics to return to a safe state (Khajehzadeh et al., 2015; Scholer and Higgins, 2013; Friedman and Förster, 2001). Prior research shows that people under prevention focus tend to engage higher cognitive resources when the effects of failure can be significant (Baumeister et al., 2001). For example, when faced with a loss in financial decision making, prevention focus people have been known to deliberately adopt a risky strategy to return to a safe state, i.e. a state of status quo (Scholer and Higgins, 2013; Scholer et al., 2010).

\section{Regulatory fit}

The promotion and prevention system are inclined to pursue a goal with approach and avoidance strategies respectively. Approach strategies fit better with a focus to ensure gains, while avoidance strategies fit better with guard against losses (Avnet and Higgins, 2006).

Normally more eagerness is involved in pursuit of gains while more vigilance is involved in the avoidance of losses (Lee and Aaker, 2004; Chernev, 2004). When promotion and prevention focused individuals adopt strategies that are consistent with their regulatory goals, they experience 'regulatory fit' (Aaker and Lee, 2006). As a result of the ensuing fit, people experience higher persuasion and purchase intentions while making product decisions.

Evidence from the domain of persuasion research shows that people experience a 'fit' when they evaluate product attributes that are relevant to a person's regulatory focus (Chatterjee et al., 2011; Lee and Aaker, 2004). Product features that support hedonic claims (e.g., great taste in yoghurt), emphasizes desirable outcome (e.g., fruit juice that helps to get 
energized), are experiential (e.g., speed of a car), appeal to the promotion system of advancement, and are therefore more influential on promotion focused individuals (Roy and Ng, 2012; Lee and Aaker, 2004; Chernev, 2004). On the other hand, product features that support utilitarian claims (e.g., useful bacteria in yoghurt), prevents undesirable outcome (e.g., fruit juice that prevents clogging of arteries) and are safety related (e.g., ABS brakes in car), appeal to the prevention system of security, and are therefore more influential on prevention focused individuals (Roy and Ng, 2012; Lee and Aaker, 2004; Chernev, 2004).

\section{Hypotheses development \\ Regulatory focus and choice of SEC attributes}

In the context of experience versus search attributes, we argue that promotion focused people will prefer the former while their counterpart will rely on the later in product decisions. A promotion system is more focused on the experiential side of consumption (Jia et al., 2012; Keller, 2006), and engages more subjective (e.g., affect and imagery) information in decision making (Das 2016; Lin and Chen 2015; Roy and Phau, 2014; Pham and Avnet, 2004). As the promotion system is about making advancement in life, these people also like to try newly launched products that engage more experiential attributes (Herzenstein et al., 2007). For example, Brakus et al. (2014) posit that successfully launched new products (e.g., the new Beetle car) focus more on providing experiential attributes (e.g., novel shapes and colors). Experience attributes which are more subjective and need to be experienced first-hand for making product decisions (Weathers et al., 2007), should therefore appeal more to the promotion system.

On the other hand, the prevention system is about making careful and deliberate decisions that relies on the practical side of consumption, like functional products (Chernev, 2004). The prevention system also engages more objective information in decision making 
that can be easily verified (Roy and Phau, 2014; Pham and Avnet, 2004). A focus on avoiding negative outcomes also causes these people to avoid ambiguous situations like experiencing newly launched products in the market (Herzenstein et al., 2007). Given that search attributes are more substantive, credible and hence can easily be verified (Lin and Chen, 2015; Weather et al., 2007, Jain and Posavac, 2004), they should appeal to the cautious nature of prevention focused people. Based on the above we hypothesize:

\author{
H1: Promotion focused individuals will exhibit higher (a) attitude and (b) \\ behavioural intention towards experience attributes in comparison to prevention- \\ focused counterparts. \\ H2: Prevention focused individuals will exhibit higher (a) attitude and (b) \\ behavioural intention towards search attributes in comparison to promotion-focused \\ counterparts.
}

\title{
Regulatory focus, attribute types and word of mouth
}

We now turn to the specific context of word of mouth's moderating influence on regulatory foci's choice of search and experience attributes. Positive word of mouth is about sharing satisfactory product experience, and may therefore signal opportunities to promotion focused individuals who are more geared towards achieving gain state (Zhang et al., 2010; Lockwood et al., 2002). Positive word of mouth should also indicate to promotion focus people that everything is fine and should further encourage their incentive seeking activities (Friedman et al., 2007). Evidence shows that promotion focus people engage with positive word of mouth by sharing them in an online environment (Das, 2016; Shin et al., 2014). In the context of product decision, providing positive online reviews strengthened promotion focus' behavioural intentions (Pentina et al., 2015). Since H1 argues that promotion focus will have 
a preference for experience attributes over their counterparts, presence of positive word of mouth will therefore only reinforce preference for the experience attributes.

As argued before, a promotion focus has the tendency to overlook risky or negative information in decision making while pursuing their agenda of advancement goals in life (Sengupta and Zhou, 2007). Further they also seem resistant to any negative information they come across in decision making. For example, after having a negative experience such as service failure, the induction of a promotion focus minimized the likelihood of spreading negative word of mouth (Shin et al., 2014). Specifically, after exposure to negative word of mouth (such as online review), promotion focus peoples' attitude and intentions were not affected by the message arguments (Pentina et al., 2015). Therefore, induction of promotion focus will reduce the impact of negative word of mouth on their preference for experiential attributes. This leads to:

\section{H3: Promotion focused individuals will exhibit higher attitude and behavioural intention towards experience attributes in comparison to prevention-focused counterparts under (a) positive word of mouth and (b) will retain these preferences under negative word of mouth.}

A positive word of mouth may also appeal to prevention focused individuals, especially by reducing uncertainty in decision making. A psychological motive underlying positive word of mouth is to signal expertise to others (Wojnicki and Godes, 2011). Further, expert judgments have been known to reduce uncertainty and risks associated with the decision making process (Cooke, 1991). In this sense, positive word of mouth will therefore alleviate decision risks by confirming to prevention people that the strategy pursued by them will not lead to negative outcome. Recent work supports this line of argument and shows that in the context of product decisions, positive word of mouth is considered by the cautious 
natured prevention focus as more persuasive to act on (Pentina et al., 2015). Based on these findings, positive word of mouth should therefore reinforce the preference for search attributes amongst these individuals as posited in $\mathrm{H} 2$.

A likely negative outcome puts prevention focus on guard and causes them to engage more cognitive resources (Baumeister et al., 2001). Prevention focus is also keen to get back to a safe or status quo state when a situation highlights the risk of imminent failure, even if it means pursuing a risky strategy (Khajehzadeh et al., 2015; Scholer and Higgins, 2013; Scholer et al., 2010; Scholer et al., 2008). Similarly, when asked to focus on failures, prevention focus people showed increased motivation to pursue strategies for avoiding failures (Lockwood et al., 2002). In the current context, negative word of mouth is more likely to raise fears of failure in prevention focus, if this strategy is pursued (Lockwood et al., 2002). Further, as negative word of mouth is more diagnostic (Lim and Chung, 2011), it is likely to influence cognitively driven prevention focus people. In response, prevention focus may actually alter their earlier preference for a specific product attribute (e.g., search), in order to achieve a safe or status quo state. This leads to:

\author{
H4: Prevention focused individuals will exhibit higher attitude and behavioural \\ intention towards search attributes in comparison to promotion-focused counterparts \\ under (a) positive word of mouth and (b) these preferences will reverse under \\ negative word of mouth.
}

We now report three studies that tests hypotheses 1 to 4 . In particular, study 1 engages a laboratory experiment to test $\mathrm{H} 1$ and $\mathrm{H} 2$, while study 2 and 3 engages a field and a laboratory experiment to test $\mathrm{H} 3$ and $\mathrm{H} 4$, albeit with a service and a product. 


\section{Study 1}

Two hundred and twenty-eight students (135 males; average age 21 years) were recruited across two large Pacific Coast universities to participate in a 2 (Regulatory focus: promotion versus prevention) x 2 (attribute type: search versus experience) between subjects' design laboratory experiment.

Pre-test: Two separate pre-tests were conducted with students, who did not participate in the main studies. In the first pre-test $(n=35)$, students were given the definition of search, experience and credence attributes, and then asked to classify a list of six university related attributes. The choice of university as the context is guided by usage of services in the word of mouth and SEC research (Lim and Chung, 2011). The attribute choice was based on extant literature (Gray et al., 2003). A list of attributes like 'ranking', 'industry connected teaching', 'theory based teaching from textbook', 'research output', 'friendly environment' and 'young and upcoming university' were tested. We selected the features that the majority (i.e. $70 \%$ or more) of students classified as a specific type. Based on the results, $100 \%$ students classified 'friendly environment', 'young and upcoming', and 92\% classified 'industry connectedness'as experience attributes. On the other hand, 100\% classified 'ranking', 'theory based teaching from textbook' and 77\% classified 'research output' as search attributes.

In a second pre-test, we once again asked a different pool of student subjects $(n=39)$ who did not participate in the main studies, as how they perceived each of these six features on a scale of 1 to 7 with end points $1=$ search attribute, and $7=$ experience attribute. In line with the regulatory focus literature discussed above, we also asked the subjects if these features varied in terms of hedonic versus utilitarian, subjective versus objective and performance versus reliability dimensions. 
We conducted a one sample ' $t$ ' test to compare each attribute with respect to the scale mid-point of 4. Consistent with findings from the first pre-test, students rated the experience attributes 'friendly environment' $(t(38)=12.64, p<0.001)$, 'young and upcoming' $(t(38)=$ $12.25, p<0.001)$, and 'industry connectedness' $(t(38)=9.89, p<0.001)$ as significantly higher than the test value. Similarly, the search attributes like 'ranking' $(t(38)=-14.74, p<$ $0.001)$, 'theory based teaching from textbook' $(t(38)=-12.44, p<0.001)$ and 'research output' $(t(38)=-8.06, p<0.001)$ were rated significantly lower than the scale mid-point. The attributes did not differ in terms of hedonic versus utilitarian, subjective versus objective and performance versus reliability dimensions (all $p \mathrm{~s}>0.1$ ). Based on these pre-tests, two separate university descriptions were created (Appendix 1).

Procedure and measures: Upon arriving in the laboratory, participants were randomly assigned to one of the four conditions. The experiment was conducted in seemingly two unrelated studies. The first part was about regulatory focus manipulation in which students were asked to write an essay about hopes and aspirations versus duties and obligations. This was based on a procedure developed and widely used in the regulatory focus literature (Pham and Avnet, 2009). In the second part, students were asked to imagine that they were considering a university for educational purposes, and were given the description of a fictitious university called 'Capital University'. The description of the university was based on 'search' or 'experience' attributes, as described earlier (see Appendix 1).

After the subjects completed the regulatory manipulation, they were asked to also undertake a manipulation check. Similarly, after reading the university descriptions, they completed a second manipulation check. Following this, a number of dependent variables like attitude and intention to study at the university were recorded. This was followed by 'involvement' and other demographic variables like age and gender. Involvement was 
measured since evidence shows that it can influence product evaluation (Vakratsas and Ambler, 1999).

Attitude towards the university was measured with seven-point scale item using variables adapted from the literature (e.g., Bennett, 2007): “The university makes me interested", "I perceive this university's reputation to be favourable", "I feel this university is trustworthy", "I trust this university to provide good quality education" (Cronbach's alpha = .956). Similarly, intention was measured with seven-point scale items adapted from the literature (e.g., Bennett 2007): "I would like to find out more information about this university, "I would probably be influenced towards going to this university", and "I will probably consider this university for my studies", (Cronbach's alpha $=.929)$. Involvement was measured with the item "While reading about the Capital university, you were", with semantic differential endpoints like "not all involved/involved" and "not at all interested/interested".

Data analysis and results

Manipulation check: Manipulation check for regulatory focus comprised of a single item about what participants considered after completing the essay, with end points like $1=$ something I ought to do and 7 = something I want to do (Pham and Avnet, 2009). The manipulation check for university type asked participants about how the university was described with end points like $1=$ search attributes, and $7=$ experience attributes.

Results of one-way ANOVA with regulatory manipulation check item showed that subjects in the promotion condition focused on something they wanted to do as against prevention focus who leaned towards something they ought to do (Ms of 5.84 versus $2.55, F(1,227)=$ $874.78, p<0.001)$. Similarly, participants' response to the description of the university based on search attributes differed significantly from the description based on experience attributes 
(Ms of 1.20 versus $6.03, F(1,227)=2715.71, p<0.001)$. The manipulation for regulatory focus and attribute type thus seems to be successful.

Covariate: Result of a two-way ANOVA with regulatory focus and attribute type showed a main effect on involvement. Subjects in the experience attribute condition were more involved in comparison to those in search attribute condition (Ms of 5.65 versus 5.02, $F(1,227)=83.2, p<0.001)$. Further, subjects in the prevention condition seemed to be more involved as compared to their promotion focused counterparts (Ms of 5.41 versus 5.25, $F(1,227)=4.36, p<0.05)$. Involvement was included as a covariate for further analyses.

Main effects: A 2 X 2 ANCOVA with attitude as the dependent variable showed a main effect of regulatory focus; subjects in the promotion focus exhibited higher attitude in comparison to their prevention focused counterparts (Ms of 4.56 versus $4.34, F(1,227)=$ $14.38, p<0.001)$. No other main effect was found to be significant. A similar ANCOVA was performed with 'intention' as the dependent variable. Results once again showed a main effect of regulatory focus $(F(1,223)=6.49, p<0.05)$ as well as attribute type $(F(1,223)=$ 50.33, $p<0.001)$. Prevention focused subjects showed higher intention over their counterparts (Ms of 4.36 versus 4.25). Further, overall the subjects showed higher intention towards the experience attributes as against the search attributes in the product description (Ms of 4.49 versus 4.12 ).

Interaction effects: As predicted by $\mathrm{H} 1$, the two-way interaction between regulatory focus and attribute type was significant for both attitude $(F(1,223)=3507.59, p<0.001)$ and intention $(F(1,223)=2374.71, p<0.001)$. Results of compared contrast analyses showed promotion subjects exhibited a higher attitude (Ms of 6.12 versus 2.92, $t(224)=50.58, p<$ 0.001 ) as well as intention (Ms of 6.17 versus $2.98, t(224)=37.34, p<0.001$ ) when the 
university was described in terms of experience attributes over their prevention counterparts. The findings support H1a and $\mathrm{b}$.

On the other hand, prevention focused subjects showed higher attitude towards the university when it was described in terms of search attributes as compared to their promotion focused counterparts (Ms of 5.83 versus $2.97, t(224)=-44.51, p<0.001)$. Similar to attitude, prevention focused subjects also showed higher intention towards the university with search attributes over promotion focused subjects (Ms of 5.80 versus 2.30, $t(224)=-40.28, p<$ 0.001). These results therefore support $\mathrm{H} 2 \mathrm{a}$ and $\mathrm{H} 2 \mathrm{~b}$. All means from study 1 are reported in tables 1 and 2.

Insert Tables 1 and 2 about here

The results obtained from the first study therefore support the key hypotheses that promotion (prevention) focused subjects preferred the experience attributes (search attributes) over their counterparts, while making a consumption decision. With these observations, we proceeded with the second study to test hypotheses 3 and 4 .

\section{Study 2}

The second study engaged a 2 (Regulatory focus: promotion versus prevention) x 2 (attribute type: search versus experience) x 2(word of mouth received: positive versus negative) between subject design in a field experiment. Four hundred and forty-nine students (192 males, mean age 25 years) participated in this study. The student participants were sourced from three highly-reputed higher education recruitment fairs held in the Asia-Pacific region 
(e.g. www.topmba.com/events) and randomly allocated to one of the eight experimental conditions.

Procedure and measures: Similar to study 1, the participants' regulatory focus was manipulated by asking them to write essays, following which they read descriptions of the fictitious university described in terms of search and experience attributes. After reading these descriptions, subjects were further asked to imagine that they met a close friend who said positive (negative) things about the university. Manipulation check items were placed after the regulatory focus and university manipulation, and the same single item measures were used from the first study. Following this, students completed key dependent variables like 'attitude' (Cronbach's alpha $=.972)$ and 'intention' (Cronbach's alpha $=.931)$ which engaged the same scales from study 1 . Further, towards the end of the experiments, participants completed involvement items, and reported their demographics.

Data analysis and results

Manipulation check: One-way ANOVA showed that subjects in promotion focus leaned towards something they wanted to do, as against prevention focus who leaned towards something they ought to do (Ms of 5.68 versus $2.11, F(1,448)=2193.31, p<0.001$ ). Similarly, subjects under the search attribute condition perceived the university description to be based on search attributes in comparison to the experience attributes (Ms of 2.13 versus $5.82, F(1,448)=2037.58, p<0.001)$. Once again, the regulatory focus and university manipulation seems to be successful.

Covariate: Results of one-way ANOVA showed that subjects demonstrated higher involvement with the search attribute as against the experience attribute (Ms of 5.69 versus $5.47, F(1,448)=30.82, p<0.001)$. Similar to study 1 , prevention focused subjects seemed to 
be more involved as compared to their counterparts (Ms of 5.65 versus 5.52, $F(1,448)=9.93$, $p<0.01)$. Involvement was thus held as a covariate in further analyses.

Main effects: Results of a three way ANCOVA with attitude as the dependent variable showed main effects of regulatory focus $(F(1,440)=714.25, p<0.001)$, and word of mouth $(F(1,440)=11449.66, p<0.001)$. Promotion focused individuals exhibited higher attitudes compared to their counterparts (Ms of 4.21 versus 3.63), while the positive word of mouth led to higher attitude compared to the negative word of mouth (Ms of 5.33 versus 2.33).

A similar three way ANCOVA was performed with intention as the dependent variable. Results once again showed that promotion focused subjects had higher intention compared to their counterparts (Ms of 4.02 versus 3.66, $F(1,440)=127.73, p<0.001$ ). Similar to attitude, higher intention was reported under positive as compared to negative word of mouth (Ms of 5.32 versus 2.48, $F(1,440)=4790.13, p<0.001)$.

Interaction effects: The two-way interaction between regulatory focus and university type was significant $(F(1,440)=836.73, p<0.001)$. This interaction was however, qualified by a significant three-way interaction between regulatory focus, university type and word of mouth $(F(1,440)=510.94, p<0.001)$. Planned contrast analyses were conducted to compare the attitudes under positive and negative word of mouth conditions.

Aligned with H3a, under positive word of mouth, promotion focused individuals showed higher attitude (Ms of 5.73 versus 4.60, $t(441)=21.82, p<0.001)$ and intention $(\mathrm{Ms}$ of 5.73 versus $4.76, t(441)=11.65, p<0.001)$ towards the university described in terms of experience attributes over their counterparts. H3a is thus supported. In support of H3b, it was found that under a negative word of mouth condition, promotion focused subjects still preferred the university with experience attributes in terms of attitude (Ms of 3.40 versus 
$1.59, t(441)=33.51, p<0.001)$ and intention (Ms of 3.19 versus $1.58, t(441)=18.56, p<$ 0.001) when compared to prevention focused people.

Under positive word of mouth, prevention focused subjects on the other hand, preferred the university with search attributes over their promotion focused counterparts in terms of both attitude (Ms of 6.28 versus $4.67, t(441)=-29.77, p<0.001)$ and intention $(\mathrm{Ms}$ of 6.41 versus $4.31, t(441)=-24.09, p<0.001)$; thereby supporting H4a. Interestingly as predicted by $\mathrm{H} 4 \mathrm{~b}$, under negative word of mouth prevention focused subjects demonstrated a preference reversal. This time around promotion focused people showed higher attitude (Ms of 3.32 versus $1.85, t(441)=30.34, p<0.001)$ and purchase intention (Ms of 3.13 versus $1.70, t(441)=18.40, p<0.001)$ for the university described in terms of search attributes in comparison to their counterparts. All the means are reported in tables 3 and 4, while figures 1, 2 and 3, 4 show the three-way interaction for 'attitude' and 'intention' respectively.

\author{
Insert Tables 3 and 4 about here \\ Insert Figures 1 and 2 about here \\ Insert Figures 3 and 4 about here
}

The above findings from study 2 show that promotion (prevention) focus preference for experience (search) attributes is sustained under positive word of mouth. However, exposure to a negative word of mouth has different implications for promotion versus prevention focused subjects. Based on the findings, promotion focused people seem to be more tolerant of negative word of mouth, and still retain their preferences for more subjective attributes e.g. experience attributes in decision making. This supports their outlook for more experiential attributes in decision making even under risky situation (Sengupta and Zhou, 2007). On the other hand, although normally prevention focused people would be risk averse; 
their reaction to a situation that connotes failure can motivate them to adopt a strategy to achieve a safe state. Once again the extant literature supports such findings (Scholer and Higgins, 2013; Scholer et al., 2010). In line with this, results from this study show that negative word of mouth may highlight the risk of a failure to prevention focused people (Lockwood et al., 2002), and under this situation, they may be willing to reverse their preferences in order to reach a safe state. In our third study we extend the findings from study 2 , to a consumer product.

\section{Study 3}

471 students (238 females, mean age 26.5 years) from a large Pacific coast university participated in 2 (Regulatory focus: promotion versus prevention) x 2 (attribute type: search versus experience) x 2 (word of mouth received: positive versus negative) between subject laboratory experiment. The participants were randomly allocated to one of the eight experimental conditions.

Pre-test: Once again a pre-test with 34 students who did not take part in the main study was conducted to decide the relevant search and experience attributes for a mobile phone. Following a description of search and experience attributes, participants were asked to categorize a number of phone attributes such as screen size, light weight, ease of usage, elegant design, high mega pixel camera, true to life videos, battery life, warranty etc. into specific category. We selected the features that majority of students classified as a specific type. Based on the results, 97\%, 100\% and 97\% categorized screen size, light weight and mega pixel as search attributes. Similarly, 97\%, 94\% and 100\% categorized ease of usage, elegant design and true to life videos as experience attributes. Once again, the attributes did not differ in terms of hedonic versus utilitarian, subjective versus objective and performance 
versus reliability dimensions (all $p \mathrm{~s}>0.1$ ). Based on this pre-test, we created search and experience based descriptions for the mobile phone (Appendix 1).

Procedure and measures: Regulatory focus was manipulated using the same technique from studies 1 and 2. For the third study we have used a different product category, mobile phone, which has been used by previous research (Roy and Sharma, 2015). Students were asked to imagine that they were shopping for a new mobile 'Vertos', following which they read one of the two descriptions (Appendix 1). After reading these descriptions, subjects were further asked to imagine that they met a close friend who said positive (negative) things about the mobile phone. Manipulation check items were placed after the regulatory focus and phone manipulation. Following this, students completed key dependent variables like 'attitude' $($ Cronbach's alpha $=.968)$ and 'intention' (Cronbach's alpha $=.945)$.

Attitude towards the brand was measured by asking "How do you rate the brand Vertos" with end points like 1 = "not interesting", "unfavourable" "undesirable", "poor quality", "bad", "unpleasant", and "worthless" and 7 = "interesting”, "favourable", “desirable", "high quality", "good”, "pleasant" and "valuable". Purchase intention was measured with four items, e.g. "I will be interested in the new Vertos", "I will probably consider the new Vertos", "I will try out the new Vertos" and "I will probably buy the new Vertos" with $1=$ "strongly disagree" and $7=$ "strongly agree" as the endpoints. Further, similar to previous experiments, participants completed involvement items, and reported their demographics towards the end.

Data analysis and results

Manipulation check: Results of one-way ANOVA showed that subjects in promotion focus leaned towards something they wanted to do, as against prevention focus who leaned towards something they ought to do (Ms of 5.89 versus $1.97, F(1,469)=2311.57, p<0.001$ ). 
Subjects in the search attributes condition perceived the mobile to be described in terms of search attributes in comparison to experience attributes (Ms of 2.2 versus 5.9, $F(1,469)=$ 2057.33, $p<0.001$ ). Both the regulatory focus and attribute manipulation thus seems to be successful.

Covariate: Results of a one-way ANOVA showed that promotion focused subjects seemed to be more involved as compared to their counterparts (Ms of 5.87 versus 5.77, $F(1,469)=4.34$, $p<0.01)$. There was no difference in involvement between search and experience attribute $($ Ms of 5.83 versus $5.81, F(1,469)=.114, p>0.05)$. Involvement was once again held as a covariate in further analyses.

Main effects: Results of a three way ANCOVA with attitude as the dependent variable showed main effects of regulatory focus $(F(1,462)=572.83, p<0.001)$, and word of mouth $(\mathrm{F}(1,462)=10308.58, p<0.001)$. Promotion focused individuals exhibited higher attitudes compared to their counterparts (Ms of 4.18 versus 3.63), while the positive word of mouth led to higher attitude compared to the negative word of mouth (Ms of 5.34 versus 2.60).

A similar three way ANCOVA was performed with intention as the dependent variable. Results once again showed that promotion focused subjects had higher intention compared to their counterparts (Ms of 4.12 versus 3.60, $F(1,462)=304.12, p<0.001$ ).

Similar to attitude, higher intention was reported under positive as compared to negative word of mouth (Ms of 5.32 versus 2.52, $F(1,462)=6715.16, p<0.001)$.

Interaction effects: The two-way interaction between regulatory focus and attribute type was significant for attitude $(F(1,462)=749.684, p<0.001)$ and purchase intention $(F(1,462)=$ $525.94, p<0.001)$. This interaction was however, qualified by a significant three-way interaction between regulatory focus, attribute type and word of mouth, once again for 
attitude $(F(1,462)=477.46, p<0.001)$, followed by purchase intention $(F(1,462)=394.95, p$ $<0.001)$. Planned contrast analyses were conducted to compare the results under positive and negative word of mouth conditions.

As predicted from $\mathrm{H} 3 \mathrm{a}$, under positive word of mouth, promotion focused individuals showed higher attitude (Ms of 5.72 versus $4.65, t(463)=19.58 p<0.001)$ and intention $(\mathrm{Ms}$ of 5.73 versus $4.63, t(463)=15.82, p<0.001)$ towards the mobile described in terms of experience attributes over their counterparts. H3a is thus supported. In support of H3b, it was found that under a negative word of mouth condition, promotion focused subjects still preferred the mobile with experience attributes in terms of attitude (Ms of 3.37 versus 1.62, $t(463)=30.96, p<0.001)$ and intention $($ Ms of 3.28 versus $1.54, t(463)=24.22, p<0.001)$ when compared to prevention focused people.

Under positive word of mouth, prevention focused subjects on the other hand, preferred the mobile with search attributes over their promotion focused counterparts in terms of both attitude (Ms of 6.27 versus 4.64, $t(463)=-28.67, p<0.001)$ and intention $($ Ms of 6.38 versus $4.48, t(463)=-26.11, p<0.001)$; thereby supporting H4a. Once again as predicted by $\mathrm{H} 4 \mathrm{~b}$, under negative word of mouth prevention focused subjects demonstrated a preference reversal. This time around, promotion focused people showed higher attitude (Ms of 3.29 versus $1.85, t(463)=28.30, p<0.001)$ and purchase intention $($ Ms of 3.25 versus $1.73, t(463)=23.33, p<0.001)$ for the mobile described in terms of search attributes in comparison to their counterparts. All the means are reported in tables 5 and 6 .

\author{
Insert Tables 5and 6 about here
}




\section{General discussion}

Across three studies, we used two different methodologies (laboratory and field experiments) and various dependent variables (attitude versus intention) to provide support for our key hypotheses. It is observed that promotion (prevention) focused subjects' preferred experience (search) attributes over their counterparts. This preference is further moderated by word of mouth valence received during decision making. Under positive word of mouth, both types of regulatory foci sustain their initial preferences, with negative word of mouth having more interesting implications. While promotion focus people retain their preferences under negative word of mouth, prevention focused people seem to exhibit a preference reversal in order to avoid any potential failure. The findings seem to be robust and are replicated with a service (university) and a product category (mobile phone).

\section{Theoretical implications}

The current work has implications for the theory of regulatory focus and word of mouth. First of all, the current work addresses call for inquiries by researchers (such as Hyo-Jin et al., 2014; Brakus et al., 2014), to understand how search and experience attributes may influence consumption. Our findings show that choice of relevant search and experience attributes is influenced by whether the target attributes help to sustain a promotion (prevention) orientation. The use of 'university' as the context for our study is interesting as it addresses both advancement and security needs in life. Extant researchers recommend studying products that addresses both promotion and prevention goals in life (Zhang et al., 2010).

The present study also contributes to a limited body of literature that connects regulatory focus with word of mouth (e.g. Zhang et al., 2010; Chung and Tsai, 2009). Further, a number of studies (Pentina et al., 2015; Lim and Chung, 2011) till date have 
reported mixed findings regarding the influence of word of mouth on product decision making for people with different regulatory orientation. The current study resolves this by proposing and testing a novel three-way interaction to show that the choice of search versus experience attributes is contingent on word of mouth valence. Existing studies that involve regulatory focus and word of mouth further do not consider the latest literature (Scholer at el., 2013), or fail to consider variables like 'product attitude' and 'behavioral intention', that are relevant for decision making (Motyka et al., 2014). The current study addresses these gaps as well. Based on recent theoretical developments that show that both promotion and prevention focus are capable of strategies that ensure desired end state (Khajehzadeh et al., 2015; Scholer et al., 2013), the current findings show that promotion focus and prevention focus decision can be reinforced under positive word of mouth. Promotion focus is relatively resistant to negative word of mouth, while their counterpart reverses their preference in order to return to a safe state (Khajehzadeh et al., 2015). Finally, the choice of dependent variables for this study, e.g., 'attitude' and 'intention' seem to be more relevant for decision making under a specific regulatory orientation (Motyka et al., 2014).

\section{Managerial implications}

The current work has important managerial implications too. Firstly, from a marketing perspective, managers may be able to strategically target their prospective consumers with relevant product attributes. For example, our findings indicate that it may be more effective to promote a product or service based on its search attributes to prevention focused people, as these features may be more appealing to these people. On the other hand, product or service that features experience attributes may appeal more to promotion focused subjects. Currently, researchers like Das (2016) posit that retailers already have existing customer information as a function of relationship management, and can probe further by asking few regulatory 
orientation questions. Once the regulatory orientation of the customer is known, our findings show that matching it with a specific product attribute can lead to effective targeting and positioning.

Similarly, matching relevant target product features in advertisements with relevant regulatory focus may enhance its effectiveness. Further, scholars argue that a regulatory state can be triggered by environmental cues like product advertisements (Labroo and Lee, 2006). For example, a shampoo ad can trigger a promotion focus while a vitamin ad can induce prevention focus (Labroo and Lee, 2006). When the triggered regulatory focus is matched with another advertisement that sustains it, matching leads to fluent information processing (Labroo and Lee, 2006). Based on our findings, a product advertisement using experience (search) attributes following a promotion or prevention focus ad should lead to more fluent information processing and enhanced persuasion (Labroo and Lee, 2006). Advertisements can also feature positive word of mouth scenarios, to further reinforce attitudes that may result from matching of regulatory focus with the relevant product or service feature.

In the marketing context, consumers often have negative consumption experiences (e.g., product failure) which could then be shared with others. Our findings show that the effect of negative word of mouth may be countered through induction of promotion focus. Specifically, while the extant literature shows that promotion focus can minimize the likelihood of spreading negative word of mouth (Shin et al., 2014), our work additionally shows that promotion focus may counteract the effect of negative word of mouth on attitude and purchase intention to a certain extent. One of the practical applications of this finding for marketing managers could be that following a negative consumption experience, they would be better off inducing advancement and aspiration goals (e.g., promotion focus) rather than focusing on prevention goals, while promoting their product or service. Our findings show 
that promotion focus may be able to counteract some of the impact from the negative word of mouth, at least relative to prevention focused people. Such findings can be strategically used by managers who promote consumer products or even services like global education (Naidoo and $\mathrm{Wu}, 2011)$.

\section{Limitations and future research}

The current work is not without limitations, some of which can provide scope for future inquiry. First of all, we have induced regulatory focus situationally to study its impact on evaluation and intention. Future work can engage chronic regulatory focus (Lockwood et al., 2002; Higgins, 1997) to study its influence on the dependent variables. Although promotion and prevention focus can be situationally salient, there are also ongoing individual differences in the extent to which people are promotion and prevention oriented, also referred to as chronic regulatory goals (Lockwood et al., 2002; Higgins, 1997). Secondly, our hypotheses can be extended by providing insights into the underlying mechanism that influence regulatory focus and word of mouth. For example, the effect of matching regulatory focus with a specific product feature on evaluation is mediated through the variable "feeling right", as matching causes consumers to feel right about the decision undertaken by them (Lee and Aaker, 2004). Future studies can therefore incorporate "feeling right" to study this mediating mechanism.

Future studies can also manipulate the word of mouth quantity, or see if the source of word of mouth giver (strong versus weak tie) has an additional influence. For example, while Chung and Tsai (2008) establish that tie strength matters for prevention focus word of mouth giver, future research can focus on how tie strength can influence the relationships discovered in the current work. Further, based on theoretical reasons and our pre-tests, we could only compare the effect of search and experience attributes, and we recommend that future study 
may consider the role of credence attributes. While the student sample used for this research seems to be justified based on extant studies (Roy and Sharma, 2015; Lin and Chen, 2015; Roy and Phau, 2014), this sampling approach also represent a potential limitation. Future research may also incorporate views of actual consumers, and may try different product category to extend the findings of the present work. Finally, given that regulatory focus can differ across culture (Das, 2016), future work can extend the current findings in a cross cultural context. 


\section{References}

Aaker, J. L. and Lee, A. Y. (2006), "Understanding regulatory fit", Journal of Marketing Research, Vol. 43 No. 1, pp. 15-19.

Avnet, T. and Higgins, E. T. (2006), "How regulatory fit affects value in consumer choices and opinions", Journal of Marketing Research, Vol. 43 No. 1, pp. 1-10.

Bansal, H.S. and Voyer, P.A. (2000), "Word of mouth processes within a services purchase decision context", Journal of Services Research, Vol. 3 No. 2, pp. 166-77.

Baumeister, R. F., Bratslavsky, E., Finkenauer, C. and Vohs, K. D. (2001), "Bad is stronger than good”, Review of General Psychology, Vol. 5 No. 4, pp. 323-370.

Bennett, R. (2007), “Advertising message strategies for encouraging young white working class males to consider entering British universities", Journal of Business Research, Vol. 60 No. 9, pp. 932-41.

Brakus, J. J., Schmitt, B. H. and Zhang, S. (2014), "Experiential product attributes and preferences for new products: The role of processing fluency", Journal of Business Research, Vol. 67 No. 11, pp. 2291-2298.

Chatterjee, S., Roy, R. and Malshe, A. V. (2011), "The role of regulatory fit on the attraction effect”, Journal of Consumer Psychology, Vol. 21 No. 4, pp. 473-481.

Chernev, A. (2004), "Goal-attribute compatibility in consumer choice", Journal of Consumer Psychology, Vol. 14 No. 1, pp. 141-150.

Chung C. M. Y. and Tsai, Q. (2009), "The effects of regulatory focus and tie strength on word-of-mouth behaviour", Asia Pacific Journal of Marketing and Logistics, Vol. 21 No. 3, pp. $329-341$.

Cooke, R. (1991), Experts in Uncertainty, New York, Oxford University Press.

Das, G. (2016), “Influence of salespersons' nonverbal communication cues on consumer shopping behaviour", Journal of Retailing and Consumer Services, Vol. 31, pp. 199206.

Das, G. (2016), "Understanding the role of regulatory focus in e-tailing activities", Journal of Services Marketing, Vol. 30 No. 2, pp. 212-222.

De Matos, A. and Rossi, C. (2008), "Word-of-mouth communications in marketing : a metaanalytic review of the antecedents and moderators", Journal of the Academy of Marketing Science, Vol. 36 No. 4, pp. 578-596.

Ekelund, R. B., Franklin, G. M. and Rand, W. R. (1995), “Advertising and information: an empirical study of search, experience and credence goods", Journal of Economic Studies, Vol. 22 No. 2, pp. 33-43. 
Eliashberg, J. and Sawhney, M. S. (1994), "Modelling goes to Hollywood: predicting individual differences in movie enjoyment", Management Science, Vol. 40 No. 9, pp.1151-1173.

Ford, G. T., Smith, D. B. and Swasy, J. L. (1990), "Consumer skepticism of advertising claims: testing hypotheses from economics of information", Journal of consumer research, Vol. 16 No. 4, pp. 433-441.

Friedman, R. S., Förster, J. and Denzler, M. (2007), "Interactive effects of mood and task framing on creative generation", Creativity Research Journal, Vol. 19 No. (2-3), pp. 141-62.

Friedman, R. S. and Förster, J. (2001), "The effects of promotion and prevention cues on creativity", Journal of Personality and Social Psychology, Vol. 81 No. 6, pp. 1001-13.

Gray B. J. , Fam, K. S. and Llanes, V.A. (2003), "Branding universities in Asian markets", Journal of Product \& Brand Management, Vol. 12 No. 2, pp.108-120.

Harrison-Walker, L.J. (2001), "The measurement of word-of-mouth communication and an investigation of service quality and customer commitment as potential antecedents", Journal of Service Research, Vol. 4 No. 1, pp. 60-75.

Herzenstein M., Posavac, S.S. and Brakus, J. (2007), “Adoption of new and really new products: the effects of self-regulation systems and risk salience, Journal of Marketing Research, Vol. 44 No. 2, pp. 251-260.

Higgins, E. T. (1997), "Beyond pleasure and pain”, American Psychologist, Vol. 52 No. 12, pp. $1280-1300$.

Hsieh, Y. C., Chiu, H. C. and Chiang, M. Y. (2005), "Maintaining a committed online customer: a study across search-experience-credence products", Journal of Retailing, Vol. 81 No. 1, pp. 75-82.

Hyo-Jin, J. J., Dant, R. P. and Gleiberman, A. M. (2014), "National versus local brands", European Journal of Marketing, Vol. 48 No. 7/8, pp. 1511 - 1535.

Jain, S. P. and Posavac, S. S. (2004), "Valenced comparisons", Journal of Marketing Research, Vol. 41 No. 1, pp. 46-58.

Jia, H., Wang, Y., Ge, L., Shi, G. and Yao, S. (2012), "Asymmetric effects of regulatory focus on expected desirability and feasibility of embracing self-service technologies", Psychology \& Marketing, Vol. 29 No. 4, pp. 209-225.

Keller, P. A. (2006), "Regulatory focus and efficacy of health messages”, Journal of Consumer Research, Vol. 33 No. 1, pp. 109-114.

Khajehzadeh, S., Oppewal, H. and Tojib, D. (2015), "Mobile coupons: what to offer, to whom, and where?", European Journal of Marketing, Vol. 49 No. 5/6, pp. 851-873. 
Klein, L. R. (1998) "Evaluating the potential of interactive media through a new lens: search versus experience goods", Journal of Business Research, Vol. 41 No. 3, pp. 195-203.

Labroo, A. A. and Lee, A. Y. (2006), "Between two brands: a goal fluency account of brand evaluation", Journal of Marketing Research, Vol. 43 No. 3, pp. 374-385.

Lee, A. Y. and Aaker, J. L. (2004), "Bringing the frame into focus: the influence of regulatory fit on processing fluency and persuasion", Journal of Personality and Social Psychology, Vol. 86 No. 2, pp. 205-218.

Lim, B. C. and Chung, C. M. (2011), "The impact of word-of-mouth communication on attribute evaluation”, Journal of Business Research, Vol. 64 No. 1, pp. 18-23.

Lin, C. H. and Chen, M. Y. (2015), "Being hooked by a brand story: a view of regulatory focus", European Journal of Marketing, Vol. 49 No. 5/6, pp. 692-712.

Lockwood, P., Jordan, C. H. and Kunda, Z. (2002), "Motivation by positive or negative role models: regulatory focus determines who will best inspire us", Journal of personality and social psychology, Vol. 83 No. 4, pp. 854- 864.

Motyka, S., Grewal D., Puccinelli, N.M., Roggeveen, A.L., Avnet, T., Daryanto, A., de Ruyter, K. and Wetzels, M. (2014), "Regulatory fit: a meta-analytic synthesis", Journal of Consumer Psychology, Vol. 24 No. 3, pp. 394-410.

Naidoo, V. and Wu. T. (2011), "Marketing strategy implementation in higher education: a mixed approach for model development and testing", Journal of Marketing Management, Vol. 27 Nos. 11/12, pp. 1117-1141.

Nelson, P. (1970), "Information and consumer behaviour", The Journal of Political Economy, Vol. 78 No. 2, pp. 311-329.

Park, C. and Lee, T. M. (2009), "Information direction, website reputation and eWOM effect: A moderating role of product type", Journal of Business Research, Vol. 62 No. 1, pp. 61-67.

Pentina, I., Bailey, A. A. and Zhang, L. (2015), "Exploring effects of source similarity, message valence, and receiver regulatory focus on yelp review persuasiveness and purchase intentions", Journal of Marketing Communications, (ahead-of-print), pp. 1-21.

Pham, M. T. and Avnet, T. (2009), "Contingent reliance on the affect heuristic as a function of regulatory focus", Organizational Behavior and Human Decision Processes, Vol. 108 No. 2, pp. 267-278.

Pham, M. T. and Avnet, T. (2004), "Ideals and oughts and the weighting of affect versus substance in persuasion”, Journal of Consumer Research, Vol. 30 No. 4, pp. 503-518. 
Roy, R. and Sharma, P. (2015), "Scarcity appeal in advertising: exploring the moderating roles of need for uniqueness and message framing," Journal of Advertising, Vol. 44 No. 4, pp. 349-359.

Roy, R. and Phau, I. (2014), "Examining regulatory focus in the information processing of imagery and analytical advertisements", Journal of Advertising, Vol. 43 No. 4, pp. 371381.

Roy, R. and Ng, S. (2012), "Regulatory focus and preference reversal between hedonic and utilitarian consumption", Journal of Consumer Behaviour, Vol. 11 No. 1, pp. 81-88.

Scholer, A. A. and Higgins, E. T. (2013), "Dodging monsters and dancing with dreams: Success and failure at different levels of approach and avoidance", Emotion Review, Vol. 5 No. 3, pp. 254-258.

Scholer, A. A., Zou, X., Fujita, K., Stroessner, S. J. and Higgins, E. T. (2010), "When risk seeking becomes a motivational necessity", Journal of Personality and Social Psychology, Vol. 99 No. 2, pp. 215-231.

Scholer, A. A., Stroessner, S. J. and Higgins, E. T. (2008), "Responding to negativity: how a risky tactic can serve a vigilant strategy", Journal of Experimental Social Psychology, Vol. 44 No. 3, pp. 767-774.

Sengupta, J. and Zhou, R. (2007), "Understanding impulsive eaters' choice behaviors: the motivational influences of regulatory focus", Journal of Marketing Research, Vol. 44 No. 2, pp. 297-308.

Shin, D., Song, J. H. and Biswas, A. (2014), "Electronic word-of-mouth (eWOM) generation in new media platforms: The role of regulatory focus and collective dissonance ", Marketing Letters, Vol. 25 No. 2, pp. 153-165.

Srinivasan, S. S. and Till, B. D. (2002), "Evaluation of search, experience and credence attributes: role of brand name and product trial", Journal of Product \& Brand Management, Vol. 11 No. 7, pp. 417-431.

Sweeney, J. C., Soutar, G. N. and Mazzarol, T. (2005), "The difference between positive and negative word-of-mouth - emotion as a differentiator", in Proceedings of the ANZMAC 2005 Conference: Broadening the Boundaries, Perth, Australia: University of Western Australia, pp. 331-337.

Vakratsas, D. and Ambler, T. (1999), "How advertising works: what do we really know?", The Journal of Marketing, Vol. 31 No. 1, pp. 26-43.

Weathers, D., Sharma, S. and Wood, S. L. (2007), "Effects of online communication practices on consumer perceptions of performance uncertainty for search and experience goods", Journal of Retailing, Vol. 83 No. 4, pp. 393-401.

Wojnicki, A. C. and Godes, D.B. (2011), "Signalling Success: Strategically Positive Word of Mouth", working paper, Rotman School of Management, University of Toronto. 
Wright, A. A. and Lynch, J. G. (1995), “Communication effects of advertising versus direct experience when both search and experience attributes are present", Journal of Consumer Research, Vol. 21 No. 4, pp. 708-718.

Yang, J. and Mai, E. S. (2010), "Experiential goods with network externalities effects : An empirical study of online rating system", Journal of Business Research, Vol. 63 No. 9, pp. 1050-1057.

Zhang J.Q, Craciun, G. and Shin D. (2010), "When does electronic word-of-mouth matter? A study of consumer product reviews", Journal of Business Research, Vol. 63 No. 12, pp. 1336-1341. 
List of Tables

Table 1: Attitude as a function of regulatory focus and attribute type

\begin{tabular}{lcc}
\hline & Search attribute & Experience attribute \\
\hline Promotion & $\mathbf{2 . 9 7}$ & $\mathbf{6 . 1 2}$ \\
& $(0.37)$ & $(0.28)$ \\
Prevention & $\mathbf{5 . 8 3}$ & $\mathbf{2 . 9 2}$ \\
& $(0.32)$ & $(0.38)$ \\
\hline
\end{tabular}

Figures in bracket denote standard deviation

Table 2: Intention as a function of regulatory focus and attribute type

\begin{tabular}{lcc}
\hline & Search attribute & Experience attribute \\
\hline Promotion & $\mathbf{2 . 3 0}$ & $\mathbf{6 . 1 7}$ \\
& $(0.42)$ & $(0.50)$ \\
Prevention & & \\
& $\mathbf{5 . 8 0}$ & $\mathbf{2 . 9 8}$ \\
& $(0.51)$ & $(0.41)$ \\
\hline
\end{tabular}

Figures in bracket denote standard deviation 
Table 3: Attitude as a function of regulatory focus, attribute type and word of mouth

\begin{tabular}{lcccc}
\hline & \multicolumn{2}{c}{ Positive WOM } & \multicolumn{2}{c}{ Negative WOM } \\
\hline & $\begin{array}{c}\text { Search } \\
\text { Attribute }\end{array}$ & $\begin{array}{c}\text { Experience } \\
\text { Attribute }\end{array}$ & $\begin{array}{c}\text { Search } \\
\text { Attribute }\end{array}$ & $\begin{array}{c}\text { Experience } \\
\text { Attribute }\end{array}$ \\
Promotion & $\mathbf{4 . 6 7}$ & $\mathbf{5 . 7 3}$ & $\mathbf{3 . 3 2}$ & $\mathbf{3 . 4 0}$ \\
& $(0.38)$ & $(0.27)$ & $(0.23)$ & $(0.24)$ \\
Prevention & $\mathbf{6 . 2 8}$ & $\mathbf{4 . 6 0}$ & $\mathbf{1 . 8 5}$ & $\mathbf{1 . 5 9}$ \\
& $(0.25)$ & $(0.26)$ & $(0.29)$ & $(0.25)$ \\
\hline
\end{tabular}

Figures in bracket denote standard deviation

Table 4: Intention as a function of regulatory focus, attribute type and word of mouth

\begin{tabular}{lcccc}
\hline & \multicolumn{2}{c}{ Positive WOM } & \multicolumn{2}{c}{ Negative WOM } \\
\hline & $\begin{array}{c}\text { Search } \\
\text { Attribute }\end{array}$ & $\begin{array}{c}\text { Experience } \\
\text { Attribute }\end{array}$ & $\begin{array}{c}\text { Search } \\
\text { Attribute }\end{array}$ & $\begin{array}{c}\text { Experience } \\
\text { Attribute }\end{array}$ \\
Promotion & $\mathbf{4 . 3 1}$ & $\mathbf{5 . 7 3}$ & $\mathbf{3 . 1 3}$ & $\mathbf{3 . 1 9}$ \\
& $(0.52)$ & $(0.53)$ & $(0.39)$ & $(0.49)$ \\
Prevention & $\mathbf{6 . 4 1}$ & $\mathbf{4 . 7 6}$ & $\mathbf{1 . 7 0}$ & $\mathbf{1 . 5 8}$ \\
& $(0.46)$ & $(0.37)$ & $(0.41)$ & $(0.31)$ \\
\hline
\end{tabular}

Figures in bracket denote standard deviation 


\section{Negative WOM}

\begin{tabular}{lcccc}
\hline & $\begin{array}{c}\text { Search } \\
\text { Attribute }\end{array}$ & $\begin{array}{c}\text { Experience } \\
\text { Attribute }\end{array}$ & $\begin{array}{c}\text { Search } \\
\text { Attribute }\end{array}$ & $\begin{array}{c}\text { Experience } \\
\text { Attribute }\end{array}$ \\
Promotion & $\mathbf{4 . 6 4}$ & $\mathbf{5 . 7 2}$ & $\mathbf{3 . 2 9}$ & $\mathbf{3 . 3 7}$ \\
& $(0.38)$ & $(0.29)$ & $(0.25)$ & $(0.25)$ \\
Prevention & $\mathbf{6 . 2 7}$ & $\mathbf{4 . 6 5}$ & $\mathbf{1 . 8 5}$ & $\mathbf{1 . 6 2}$ \\
& $(0.28)$ & $(0.26)$ & $(0.33)$ & $(0.29)$ \\
\hline
\end{tabular}

Table 5: Attitude as a function of regulatory focus, attribute type and word of mouth

Figures in bracket denote standard deviation

\begin{tabular}{lcccc}
\hline & \multicolumn{2}{c}{ Positive WOM } & \multicolumn{2}{c}{ Negative WOM } \\
\hline & $\begin{array}{c}\text { Search } \\
\text { Attribute }\end{array}$ & $\begin{array}{c}\text { Experience } \\
\text { Attribute }\end{array}$ & $\begin{array}{c}\text { Search } \\
\text { Attribute }\end{array}$ & $\begin{array}{c}\text { Experience } \\
\text { Attribute }\end{array}$ \\
Promotion & $\mathbf{4 . 4 8}$ & $\mathbf{5 . 7 3}$ & $\mathbf{3 . 2 5}$ & $\mathbf{3 . 2 8}$ \\
& $(0.48)$ & $(0.42)$ & $(0.34)$ & $(0.37)$ \\
Prevention & $\mathbf{6 . 3 8}$ & $\mathbf{4 . 6 3}$ & $\mathbf{1 . 7 3}$ & $\mathbf{1 . 5 4}$ \\
& $(0.36)$ & $(0.34)$ & $(0.41)$ & $(0.26)$
\end{tabular}

Table 6: Intention as a function of regulatory focus, attribute type and word of mouth

Figures in bracket denote standard deviation 


\section{List of figures}

Figure 1: Attitude as a function of regulatory focus and attribute type under PWOM

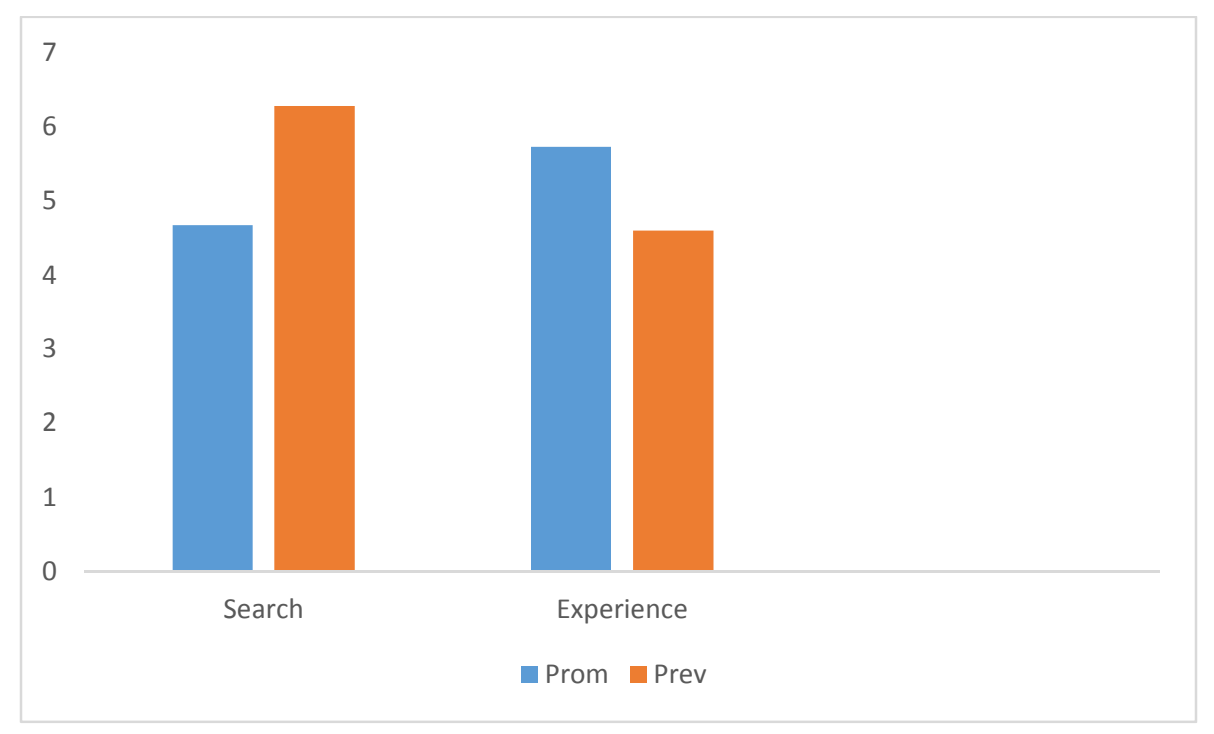

Figure 2: Attitude as a function of regulatory focus and attribute type under NWOM

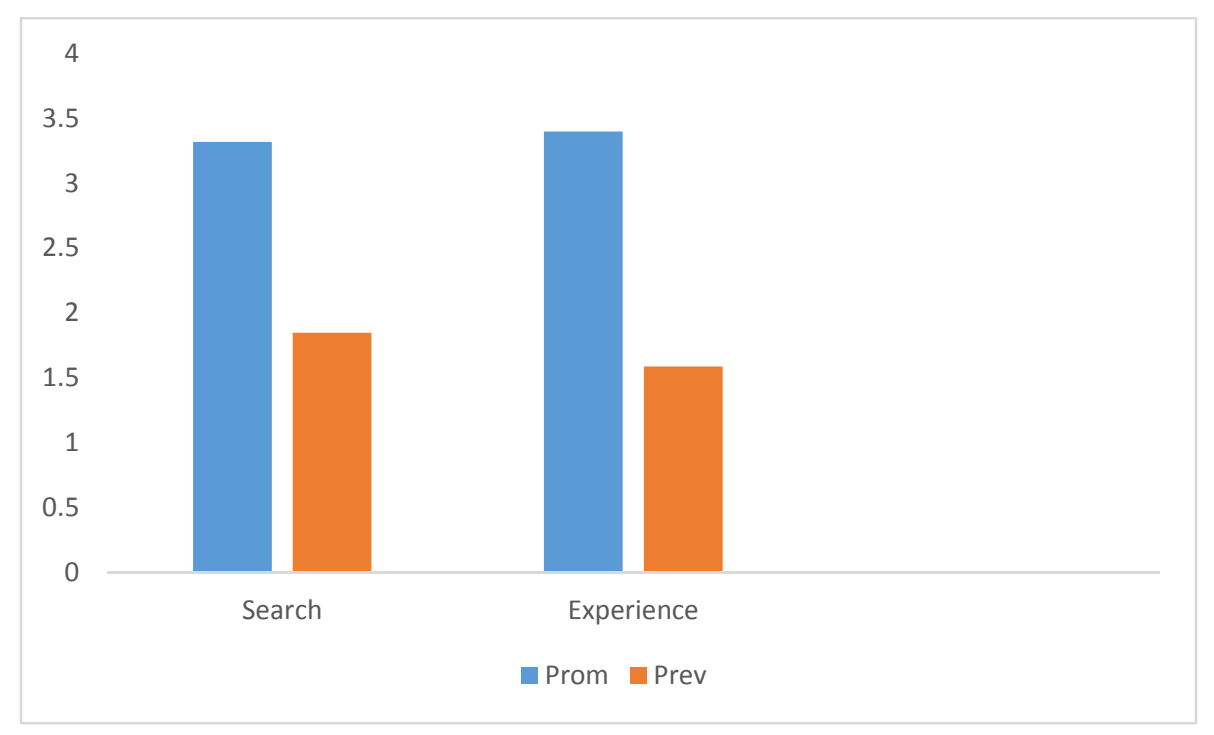


1

2

3

4

5

6

7

8

9

10

11

12

13

14

15

16

17

18

19

20

21

22

23

24

25

26

27

28

29

30

31

32

33

34

35

36

37

38

39

40

41

42

43

44

45

46

47

48

49

50

51

52

53

54

55

56

57

58

59

60

Figure 3: Intention as a function of regulatory focus and attribute type under PWOM

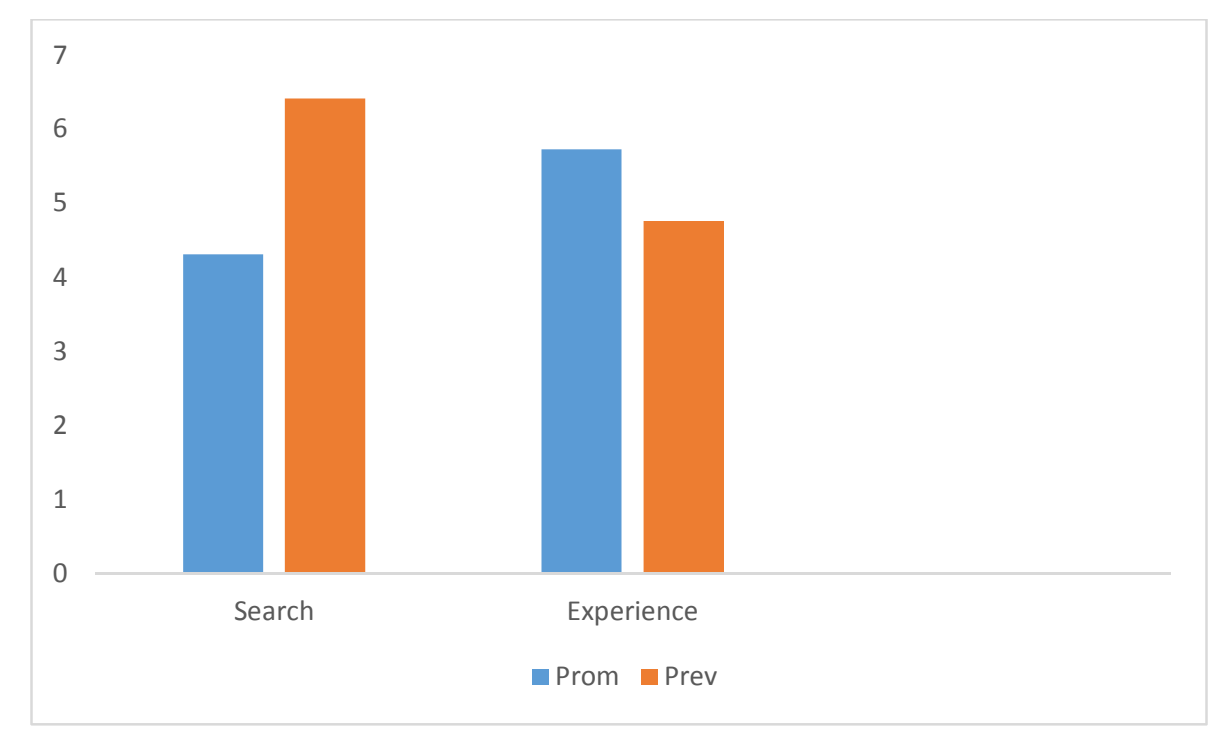

Figure 4: Intention as a function of regulatory focus and attribute type under NWOM

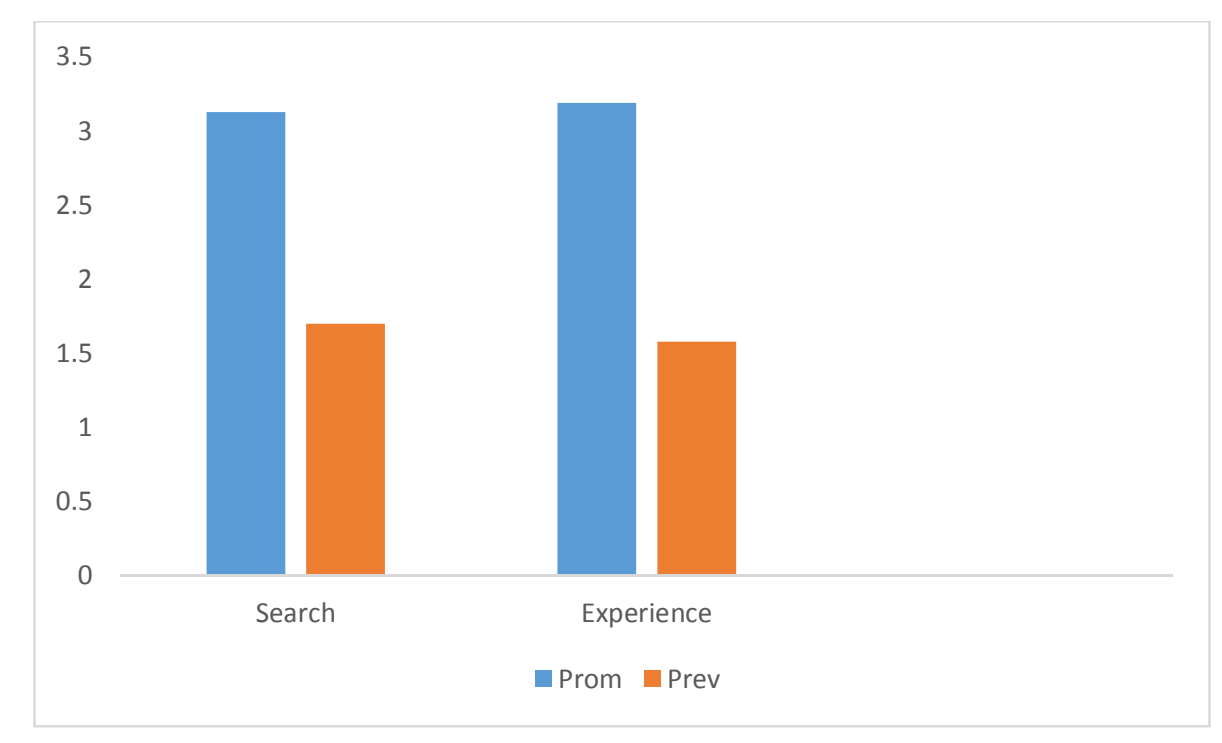




\section{Appendix 1}

\section{Study 1 and 2}

\section{University with search attributes}

Imagine you are in your home country, and in the process of selecting an overseas university for your degree. You come across this university called "Capital University" located in a multicultural city of a developed country. The university's faculty is known for their high quality research output and the institute is amongst the globally ranked ones. The academics are also known to engage theory based teaching straight from text books.

\section{University with experience attributes}

Imagine you are in your home country, and in the process of selecting an overseas university for your degree. You come across this university called "Capital University" located in a multicultural city of a developed country. The university's faculty is known for their friendly approach and the institute is amongst the young and upcoming ones. The academics are also known to engage a teaching style that connects theory to industry relevant practices.

\section{Study 3}

\section{Mobile phone with search attributes}

Imagine you are in the market for a new smartphone. As you were flipping through a consumer magazine you come across a brand called 'Vertos' launched by a leading smartphone manufacturer. The smartphone is highly rated for its big screen size, light weight and a high mega pixel camera. Overall, you liked the description.

\section{Mobile phone with experience attributes}

Imagine you are in the market for a new smartphone. As you were flipping through a consumer magazine you come across a brand called 'Vertos' launched by a leading 
1

2

3

4

5

6

7

8

9

10

11

12

13

14

15

16

17

18

19

20

21

22

23

24

25

26

27

28

29

30

31

32

33

34

35

36

37

38

39

40

41

42

43

44

45

46

47

48

49

50

51

52

53

54

55

56

57

58

59

60 smartphone manufacturer. The smartphone is highly rated for its ease of usage, elegant design, and for true to life videos. Overall, you liked the description. 